\title{
Rheumatic heart disease in the Eastern Mediterranean Region ${ }^{1}$
}

Citation: Rheumatic heart disease in the Eastern Mediterranean Region. East Mediterr Health J. 2019;25(4):292-293 https://doi.org/10.26719/2019.25.4.292 Copyright @ World Health Organization (WHO) 2019. Some rights reserved. This work is available under the CC BY-NC-SA 3.0 IGO license (https:// creativecommons.org/licenses/by-nc-sa/3.o/igo).

\section{Introduction}

To support implementation of resolution WHA71/14 of the Seventy-first World Health Assembly (1) on rheumatic fever and rheumatic heart disease (2), passed in May 2018, the WHO Regional Office for the Eastern Mediterranean held a technical consultative meeting on rheumatic heart disease, in partnership with the World Heart Federation, in Cairo, Egypt, 21-22 January, 2019 (3). The meeting provided an opportunity to discuss a draft regional framework for action to address rheumatic fever and rheumatic heart disease in endemic countries of the Eastern Mediterranean Region. The proposed regional framework seeks to operationalize the World Health Assembly resolution, guiding countries in developing/ adapting comprehensive national programmes.

The objectives of the meeting were to:

- assess the national capacity, health systems barriers, and needs of Member States of the WHO Eastern Mediterranean Region in relation to the prevention and control of rheumatic fever and rheumatic heart disease;

- review a draft regional framework for action for rheumatic heart disease prevention and control;

- discuss the terms of reference for a regional rheumatic fever/rheumatic heart disease expert network; and

- share information and best practices on rheumatic heart disease prevention and control in the Region, including site visits to Egyptian rheumatic heart disease clinics.

The meeting was attended by representatives from ministries of health, global and regional experts, representatives from Reach and the World Heart Federation, and staff from the WHO Regional Office for the Eastern Mediterranean.

Dr Asmus Hammerich, Director, Noncommunicable Diseases and Mental Health, and Dr Slim Slama, Regional Advisor, Noncommunicable Diseases Prevention, WHO Regional Office for the Eastern Mediterranean, welcomed participants and outlined the current global momentum to address rheumatic fever and rheumatic heart disease, following the passing of the World Health Assembly resolution, along with the background to WHO's engagement in this area of work and the objectives of the meeting.

\section{Summary of discussions}

There was discussion on the inclusion of the social determinants of health as a strategic approach, given the limited scope of the health sector to influence broader policy issues. While recognizing that capacity to influence may be limited, it was agreed that social determinants of health would be retained as one of the framework's strategic approaches.

It was proposed that the strategic approach of "community education", be renamed "community awareness". In addition, with regard to the strategic approach of "community and primary health care workforce", it was proposed that the title be changed to avoid ambiguity and potential misinterpretation that the domain relates not to the health workforce, but to the broader community/general population.

In relation to the strategic approach of "surveillance and research", there was discussion on the expectation and requirement that countries should develop or implement a priority research agenda. It was concluded that this would be an option for countries, but should not be considered a requirement. A change in the title of this domain was proposed to "surveillance and monitoring", while retaining a mention of research as a progress indicator. Likewise, the issue of whether countries should be required to make rheumatic fever a notifiable condition was discussed. It was agreed that this should not be a requirement, but rather identified in the framework as an option for countries to consider, according to national needs.

Regarding primary and secondary prevention, it was agreed that the wording should make more explicit the need to achieve integration.

Reproductive health was noted as an important area that should be explicitly mentioned, and highlighted as an opportunity for integration with existing service delivery platforms.

Benzathine penicillin G (BPG) quality testing was raised as an important issue for countries to consider, given the concerns in many countries regarding adverse events and quality control. It was agreed that this should be mentioned as an issue that countries should give consideration to in regard to the measures that can reasonably be taken to assure quality.

The draft regional framework for action on rheumatic heart disease prevention and control will be presented at

This report is extracted from the Summary report on the Consultative meeting on rheumatic disease in the Eastern Mediterranean Region, Cairo,

Egypt, 21-22 January 2019 (http://applications.emro.who.int/docs/IC_Meet_Rep_2019_23550_en.pdf?ua=1). 
the next session of the Regional Committee for the WHO Eastern Mediterranean, to be held in Tehran, Islamic Republic of Iran, during October 2019.

\section{Next steps}

- Refine the situational analysis by integrating input from country focal points/representatives, and devel- op a regional synopsis identifying key priorities and opportunities.

- Disseminate the regional synopsis to Member States.

- A draft agenda will be created for the first rheumatic fever/rheumatic heart disease expert network meeting.

\section{References}

1. World Health Organization. Preparation for the third High-level Meeting of the General Assembly on the Prevention and Control of Non-communicable Diseases, to be held in 2018 - report by the director-General. Geneva: World Health Organization; 19 April 2018 (https://apps.who.int/gb/ebwha/pdf_files/WHA71/A71_14-en.pdf).

2. Seventy-first World Health Assembly. Resolution WHA71.154. Geneva: World Health Assembly; 2018 (https://apps.who.int/gb/ ebwha/pdf_files/WHA71/A71_R14-en.pdf).

3. World Health Organization Regional Office for the Eastern Mediterranean. Summary report on the Consultative meeting on rheumatic disease in the Eastern Mediterranean Region, Cairo, Egypt, 21-22 January 2019 (http://applications.emro.who.int/docs/ IC_Meet_Rep_2019_23550_en.pdf?ua=1).

The State of Kuwait Prize for the Control of Cancer, Cardiovascular Diseases and Diabetes Foundation, in the Eastern Mediterranean Region is one of the several foundation prizes, administered by the World Health Organization, created to acknowledge the work of well-known scientists, researchers or simply dedicated people who have made an outstanding contribution in prevention, control and research in one or more of the following disease groups:

Cancer, Cardiovascular Disease and Diabetes in the Eastern Mediterranean Region.

The prize consists of a certificate of award, a bronze medal and a sum of USD 5,000 to be presented during the applicable session of the World Health Organization Regional Committee for the Eastern Mediterranean by its Chairman.

For more information about the eligibility and the online application form please visit the following link: http://kuwaitprize.emro.who.int/ 